\title{
Population characteristics related to colorectal cancer testing in New South Wales, Australia: results from the 45 and Up Study cohort
}

\author{
Marianne F Weber, Emily Banks, Robyn Ward and Freddy Sitas
}

J Med Screen 2008;15:137-142

DOI: $10.1258 /$ ims.2008.008050

See end of article for authors' affiliations

..............

Correspondence to: Marianne F Weber, Research Fellow, Cancer Epidemiology Research Unit, The Cancer Council NSW, PO Box 572, Kings Cross 1340, Australia; mariannew@nswcc.org.au

Accepted for publication 25 August 2008

\begin{abstract}
Objective To compare the characteristics of people who utilize colorectal cancer screening tests with those who do not.

Setting Self-reported questionnaire data from 15,900 women and 14,953 men aged 50 or over who had never had colorectal cancer were taken from the 45 and Up Study cohort in Australia in 2006.

Methods A cross-sectional analysis of colorectal cancer test behaviour within the last five years by faecal occult blood test (FOBT), or by any test (FOBT, sigmoidoscopy or colonoscopy) was performed. Results A total of $36.2 \%$ of participants reported colorectal cancer testing and $17.9 \%$ reported having a FOBT. Both FOBT and any testing were reduced significantly in groups with the following attributes compared with the remaining population; ages 50-59 and 80+; female; no family history of colorectal cancer; lower education; lower income; not speaking English at home; lack of private health insurance; not being retired; not living with a partner and not having other screening tests. Compared with other participants, test uptake was particularly low among current smokers (relative risk $0.76,95 \% \mathrm{Cl} 0.71-0.80)$, sedentary participants $10.71,95 \% \mathrm{Cl} 0.66-$ $0.77)$, those without fruit $(0.77,95 \% \mathrm{Cl} 0.71-0.84)$ or vegetables $(0.79,95 \% \mathrm{Cl} 0.69-0.90)$ in their daily diet and those with a disability $(0.91,95 \% \mathrm{Cl} 0.85-0.97)$. Compared with participants from major cities, outer regional area participants were significantly more likely to report a $\mathrm{FOBT}(1.31,95 \% \mathrm{Cl} 1.23-1.39)$ however participants in remote areas were significantly less likely to have had any colorectal cancer test $(0.75,95 \% \mathrm{Cl} 0.67-0.85)$.
\end{abstract}

Conclusion Subgroups of the Australian population may require targeted intervention to ensure equity in colorectal cancer screening.
$\mathrm{T}$ he incidence and mortality rates of colorectal cancer in Australia are among the highest in the world. ${ }^{1}$ The majority of colorectal cancers start from adenomatous polyps and screening trials have shown that identification and removal of polyps reduces the incidence of colorectal cancer. ${ }^{2,3}$ Australian national guidelines recommend that asymptomatic people aged 50 years and over be screened for colorectal cancer with a faecal occult blood test (FOBT) at least once every two years, and possibly with flexible sigmoidoscopy once every five years. ${ }^{4}$ However, since the introduction of the guidelines in 1999, consumer access to colorectal screening tests has not been freely available and screening coverage for colorectal cancer remains low. ${ }^{5}$ Australia is now phasing in a National Bowel Cancer Screening Program using FOBT and an important part of its evaluation process will be identifying factors associated with participation. However, in Australia little is known about the factors affecting uptake of colorectal cancer screening.

This paper describes demographic, lifestyle and health-related factors related to colorectal cancer testing in a large cohort study of people aged 45 and over in New South Wales (NSW) that commenced just prior to the onset of the National Bowel Cancer Screening Program.
The aim of the paper was to provide an indication of the types of people who undertook colorectal cancer testing prior to commencement of the national programme, and identify subgroups of the population that may be less likely to participate.

\section{METHODS}

\section{Study population}

The 45 and Up Study is a population-based cohort study of people aged 45 and over in NSW, Australia. ${ }^{6}$ Participants are randomly selected from the Medicare Australia enrolment database, which includes all citizens and permanent residents of Australia, as well as some temporary residents and refugees. There is oversampling of residents in regional and remote areas and those aged 80 and over, and the response rate is estimated at $18 \%{ }^{6}$ Participants complete a mailed self-administered questionnaire and consent form (available at www.45andUp.org.au). This paper uses questionnaire data from 31,401 people aged 50 and over who joined the study from February to June 2006. 


\section{Ascertainment of testing behaviour and its predictors}

History of colorectal cancer testing was ascertained among participants from the question 'Have you ever been screened for colorectal (bowel) cancer?' Respondents who marked 'yes' were asked to indicate whether the test had been a 'FOBT (test for blood in the stool/faeces)?', 'a sigmoidoscopy (a tube is used to examine the lower bowel: this is usually done in a doctor's office without pain relief)?' or 'a colonoscopy (a long tube is used to examine the whole large bowel; you would usually have to have an enema or drink large amounts of special liquid to prepare the bowel for this)?'. Participants were then asked, 'About how many years ago was the most recent one of these tests?'. It should be noted that although the questionnaire items concern 'screening' specifically, it is possible that some of the colonoscopies reported here were for diagnostic testing rather than screening. Therefore, analyses that include colonoscopy are described as colorectal 'testing' rather than 'screening'. In contrast, reported use of FOBT is likely to reflect colorectal screening specifically.

For clarity of interpretation, the main analyses exclude participants who reported a personal history of colorectal cancer as these individuals would be undergoing more frequent surveillance. All analyses were adjusted for family history of certain cancer types for similar reasons, which was ascertained from the question 'Have your mother, father, brother(s) or sister(s) ever had: breast cancer?, bowel cancer?, lung cancer?, melanoma?, prostate cancer? ovarian cancer?'.

All demographic factors analysed are listed in Table 1. Common lifestyle factors used for analysis were those that are known or suspected to impact the incidence of colorectal cancer or the decision to be tested or screened. These are shown in Tables 2 and 3 and classed, where possible, as either meeting or not meeting Australian or international guidelines. $^{7-9}$

\section{Analyses}

The first of two analyses compared the characteristics of users and non-users of FOBT within the last five years (whether they also reported using another test, or not), and the second compared those who had any test within the last five years (i.e. FOBT, colonoscopy or sigmoidoscopy) with those that did not.

Generalized linear models with binomial distribution and $\log$ link function were used to estimate the relative risk(RR) and $95 \%$ confidence interval (CI) of being tested, by demographic and lifestyle factors. ${ }^{10}$ Each model was adjusted for gender, age (four levels: 50-59, 60-69, 70-79, 80+) and family history of cancer (none, bowel cancer, other cancer). A $\chi^{2}$ test for trend, adjusting for all other stratification levels, was used to test for significance across exposure levels where appropriate. All models included a term for missing variables.

\section{RESULTS}

Of the 31,401 participants, 548 reported a previous diagnosis of colorectal (bowel) cancer and were excluded from all analyses. Other exclusions included 198 men and 131 women who provided insufficient information regarding FOBT use, leaving 14,755 men and 15,769 women for these analyses. A total of 417 men and 288 women provided insufficient information on the use of any colorectal cancer test and were excluded, leaving 14,536 men and 15,612 women for analyses of colorectal cancer testing with any type of test. Risk estimates based on all variables examined did not differ substantially between the sexes, therefore results for men and women are combined.

Overall, $36.2 \%$ of participants aged 50 years or older reported that they had been tested for bowel cancer and $17.9 \%$ reported having a FOBT within the last five years.

\section{FOBT use}

Men were more likely to report a FOBT than women, as were those aged 60-79 compared with those aged 50-59 and $80+($ Table 1$)$. Participants reporting a family history of bowel cancer were $20 \%$ more likely to have had a FOBT than participants without. Adjusting for gender, age and family history of bowel cancer, use of FOBT was associated with higher education, living in regional areas, annual pre-tax incomes greater than $\$ 20,000$, having private or Department of Veterans Affairs health insurance, being partially or fully retired or looking after home/family, living with a partner, speaking only English at home, and having other cancer screening tests (i.e. for breast or prostate cancer). There was a significant trend of increasing likelihood of FOBT use with increasing education $\left(\chi_{1}^{2}=185.76\right.$, $P<0.0001)$ and income $\left(\chi_{1}^{2}=117.89, P<0.0001\right)$.

FOBT use within the last five years was reduced among current smokers, those who were sedentary or did not meet national recommendations for adequate amounts of physical activity, and those who were underweight (body mass index $\left.[\mathrm{BMI}]<18.5 \mathrm{~kg} / \mathrm{m}^{2}\right)$ or obese $\left(\mathrm{BMI}>30 \mathrm{~kg} / \mathrm{m}^{2}\right)$ compared with those of normal weight (Table 2). FOBT uptake increased with better levels of self-rated health (test for trend: $\chi_{1}^{2}=90.90, P<0.0001$ ) and quality of life (test for trend: $\left.\chi_{1}^{2}=117.15, P<0.0001\right)$, and those who reported needing help with daily tasks were less likely to have had a FOBT than those who did not.

Dietary factors associated with low usage of FOBT included low, or no, daily serves of fruit or vegetables, insufficient amounts of unprocessed cereals, and those who reported not eating red meat (Table 3). Those who mostly use reduced fat, skim or soy milk, or reported not drinking milk at all, were more likely to have used a FOBT than those who used whole milk. Weekly serves of processed meat were not associated with FOBT use. Participants who reported taking vitamin supplements were more likely to have used a FOBT than those who did not, as were those who reported taking aspirin for the heart.

\section{Testing with FOBT, sigmoidoscopy or colonoscopy}

The demographic characteristics of participants who used any test for colorectal cancer in the last five years are also presented in Table 1. The results here are similar to those for FOBT use except that the point estimates are generally closer to one. That is, gender, age, education, family history of cancer, income, insurance, work status, relationship status, language and uptake of other cancer screening tests were all associated with colorectal cancer testing with any test type. There was a significant trend of increasing likelihood of colorectal cancer testing with increasing education $\left(\chi_{1}^{2}=99.94, \quad P<0.0001\right)$ and income $\left(\chi_{1}^{2}=147.81\right.$, $P<0.0001)$. The one demographic variable that differed between the two series of analyses in terms of test uptake was place of residence. Those who lived in remote areas were less likely to be tested overall than those in urban and 
Table 1 Distribution of colorectal test uptake by demographic variables

\begin{tabular}{|c|c|c|c|c|c|c|c|c|}
\hline \multirow[b]{2}{*}{ Demographics } & \multicolumn{4}{|c|}{ FOBT only $n=5518$} & \multicolumn{4}{|c|}{ All tests* $n=11158$} \\
\hline & Uptake (n) & Uptake (\%) & $\mathrm{RR}^{\dagger}$ & $95 \% \mathrm{Cl}$ & Uptake (n) & Uptake (\%) & $\mathrm{RR}^{\dagger}$ & $95 \% \mathrm{Cl}$ \\
\hline \multicolumn{9}{|l|}{ Gender } \\
\hline Female & 2544 & 16 & 1.0 & & 5405 & 34 & 1.0 & \\
\hline Male & 2974 & 20 & 1.27 & $1.21-1.33$ & 5753 & 38 & 1.13 & $1.09-1.16$ \\
\hline \multicolumn{9}{|l|}{ Age } \\
\hline $50-59^{\ddagger}$ & 1884 & 16 & 1.0 & & 3737 & 31 & 1.0 & \\
\hline $60-69$ & 2041 & 22 & 1.38 & $1.30-1.46$ & 3910 & 42 & 1.31 & $1.26-1.35$ \\
\hline $70-79$ & 1162 & 20 & 1.24 & $1.16-1.33$ & 2381 & 40 & 1.26 & $1.21-1.31$ \\
\hline $80+$ & 431 & 12 & 0.76 & $0.69-0.84$ & 1130 & 32 & 1.01 & $0.96-1.07$ \\
\hline \multicolumn{9}{|l|}{ Family history } \\
\hline None $^{\ddagger}$ & 2911 & 17 & 1.0 & & 5530 & 32 & 1.0 & \\
\hline Bowel cancer & 872 & 20 & 1.20 & $1.12-1.29$ & 2439 & 56 & 1.74 & $1.68-1.80$ \\
\hline Other cancer ${ }^{\S}$ & 1735 & 19 & 1.13 & $1.07-1.19$ & 3189 & 35 & 1.09 & $1.06-1.13$ \\
\hline \multicolumn{9}{|l|}{ Education } \\
\hline None $^{\ddagger}$ & 545 & 12 & 1.0 & & 1409 & 31 & 1.0 & \\
\hline School certificate & 1230 & 17 & 1.41 & $1.29-1.55$ & 2643 & 36 & 1.17 & $1.11-1.23$ \\
\hline $\mathrm{HSC} /$ trade & 2367 & 19 & 1.55 & $1.42-1.69$ & 4643 & 37 & 1.19 & $1.13-1.24$ \\
\hline University & 1376 & 22 & 1.88 & $1.71-2.06$ & 2463 & 39 & 1.30 & $1.24-1.37$ \\
\hline \multicolumn{9}{|l|}{ ARIA** } \\
\hline Major city & 2034 & 16 & 1.0 & & 4598 & 36 & 1.0 & \\
\hline Inner region & 2112 & 19 & 1.15 & $1.09-1.22$ & 4101 & 36 & 0.99 & $0.96-1.03$ \\
\hline Outer region & 1269 & 22 & 1.31 & $1.23-1.39$ & 2242 & 38 & 1.02 & $0.98-1.06$ \\
\hline Remote & 101 & 13 & 0.79 & $0.65-0.95$ & 211 & 27 & 0.75 & $0.67-0.85$ \\
\hline \multicolumn{9}{|c|}{ Annual household income $e^{\dagger \dagger}$} \\
\hline $0-19 k^{\ddagger}$ & 1048 & 15 & 1.0 & & 2347 & 33 & 1.0 & \\
\hline $20-49 k$ & 1661 & 21 & 1.42 & $1.32-1.52$ & 3160 & 39 & 1.23 & $1.18-1.28$ \\
\hline $50 k+$ & 1641 & 20 & 1.52 & $1.41-1.64$ & 3113 & 39 & 1.31 & $1.26-1.37$ \\
\hline Won’t disclose & 985 & 17 & 1.21 & $1.12-1.31$ & 2100 & 36 & 1.15 & $1.10-1.21$ \\
\hline \multicolumn{9}{|l|}{ Health insurance status } \\
\hline None ${ }^{\ddagger}$ & 565 & 13 & 1.0 & & 1117 & 26 & 1.0 & \\
\hline Health care card & 863 & 14 & 0.99 & $0.90-1.09$ & 1903 & 31 & 1.08 & $1.01-1.15$ \\
\hline Dept. Vet. Affairs & 201 & 15 & 1.26 & $1.07-1.48$ & 514 & 38 & 1.40 & $1.28-1.53$ \\
\hline Private & 2872 & 21 & 1.54 & $1.42-1.68$ & 5592 & 41 & 1.49 & $1.42-1.57$ \\
\hline Private with extras & 950 & 20 & 1.45 & $1.32-1.59$ & 1850 & 39 & 1.39 & $1.31-1.48$ \\
\hline \multicolumn{9}{|l|}{ Work status } \\
\hline Full time ${ }^{\ddagger}$ & 899 & 16 & 1.0 & & 1794 & 32 & 1.0 & \\
\hline Self-employed & 461 & 17 & 1.02 & $0.92-1.13$ & 916 & 34 & 1.01 & $0.95-1.07$ \\
\hline Home care & 332 & 17 & 1.15 & $1.02-1.30$ & 688 & 35 & 1.10 & $1.02-1.18$ \\
\hline Retired & 2653 & 19 & 1.20 & $1.10-1.31$ & 5469 & 39 & 1.11 & $1.06-1.17$ \\
\hline Partially retired & 498 & 25 & 1.46 & $1.32-1.62$ & 861 & 44 & 1.22 & $1.15-1.30$ \\
\hline Other & 675 & 15 & 0.97 & $0.88-1.06$ & 1430 & 132 & 0.98 & $0.93-1.04$ \\
\hline \multicolumn{9}{|l|}{ Relationship status } \\
\hline Partner ${ }^{\ddagger}$ & 4459 & 20 & 1.0 & & 8685 & 38 & 1.0 & \\
\hline Single & 1050 & 13 & 0.72 & $0.67-0.76$ & 2452 & 31 & 0.83 & $0.80-0.86$ \\
\hline \multicolumn{9}{|c|}{ Language spoken at home } \\
\hline English ${ }^{\ddagger}$ & 5270 & 19 & 1.0 & & 10486 & 37 & 1.0 & \\
\hline Other & 248 & 10 & 0.52 & $0.46-0.59$ & 672 & 26 & 0.74 & $0.69-0.79$ \\
\hline \multicolumn{9}{|l|}{ Other screening tests } \\
\hline $\begin{array}{l}\mathrm{No}^{\ddagger} \\
\text { Yes }\end{array}$ & $\begin{array}{r}618 \\
4900\end{array}$ & $\begin{array}{l}10 \\
20\end{array}$ & $\begin{array}{l}1.0 \\
2.21\end{array}$ & & $\begin{array}{l}1355 \\
0803\end{array}$ & 22 & 1.0 & \\
\hline Yes & 4900 & 20 & 2.21 & $2.04-2.40$ & 9803 & 40 & 1.93 & $1.84-2.03$ \\
\hline
\end{tabular}

Abbreviations: FOBT faecal occult blood test; RR relative risk; $\mathrm{Cl}$ confidence interval

* Includes FOBT, colonoscopy or sigmoidoscopy

${ }^{\dagger}$ Adjusted for age, gender and family history of cancer. Numbers may not add up to total due to missing values

¥Reference category

\$Meference category
${ }^{+}$Major cancer types within immediate family only, i.e. cancers of the breast, lung, melanoma, prostate, or ovaries

**Place of residence using the mean Accessibility/Remoteness Index of Australia (ARIA+; see www.abs.gov.au)

${ }^{\dagger}$ Pre-tax household annual income

${ }^{\ddagger \ddagger}$ Mammography or Prostate Specific Antigen test

regional areas, whereas those who lived in regional areas were most likely to have had a FOBT.

The proportion of participants who reported colorectal cancer testing in the last five years was low among those who were classified as obese II/III compared with participants in the normal weight range (Table 2). Similar to analyses on FOBT, low uptake of any colorectal cancer test was associated with current smoking and insufficient levels of physical activity. Uptake was also low among those who rated their quality of life as poor (test for trend: $\left.\chi_{1}^{2}=27.51, P<0.0001\right)$, and was not associated with overall health (test for trend: $\chi_{1}^{2}=3.62, P=0.06$ ).
Participants who needed help with daily tasks were only slightly less likely to be tested for colorectal cancer than others.

Dietary factors associated with low rates of colorectal cancer testing included no, or low, daily serves of fruit or vegetables, low amounts of unprocessed cereals, and no weekly serves of red meat (Table 3). Those who mostly use reduced fat, skim or soy milk, or reported not drinking milk at all, were more likely to be tested for colorectal cancer than those who used whole or 'other' types of milk. Weekly serves of processed meat was not associated with test uptake. Similar to FOBT uptake, use of vitamin 
Table 2 Distribution of colorectal test uptake by lifestyle factors

\begin{tabular}{|c|c|c|c|c|c|c|c|c|}
\hline \multirow[b]{2}{*}{ Health and lifestyle factors } & \multicolumn{4}{|c|}{ FOBT only $n=5518$} & \multicolumn{4}{|c|}{ All tests* $n=11158$} \\
\hline & Uptake $(n)$ & Uptake (\%) & $\mathrm{RR}^{\dagger}$ & $95 \% \mathrm{Cl}$ & Uptake $(n)$ & Uptake (\%) & $\mathrm{RR}^{\dagger}$ & $95 \% \mathrm{Cl}$ \\
\hline \multicolumn{9}{|l|}{ BMI Range $\left(\mathrm{kg} / \mathrm{m}^{2}\right)^{\ddagger}$} \\
\hline $\begin{array}{l}\text { Underweight }(<18.5) \\
\text { Normal }(18.5-24.9)^{\S}\end{array}$ & $\begin{array}{r}61 \\
2065\end{array}$ & $\begin{array}{l}14 \\
19\end{array}$ & $\begin{array}{l}0.78 \\
1.0\end{array}$ & & $\begin{array}{r}145 \\
3977\end{array}$ & $\begin{array}{l}33 \\
36\end{array}$ & $\begin{array}{l}0.92 \\
1.0\end{array}$ & $0.80-1.04$ \\
\hline Overweight (25.0-29.9) & 2238 & 20 & 0.98 & $0.93-1.03$ & 4372 & 38 & 1.03 & $1.00-1.06$ \\
\hline Obese I $(30-34.9)$ & 668 & 15 & 0.77 & $0.71-0.83$ & 1518 & 35 & 0.94 & $0.90-0.98$ \\
\hline Obese II/III $(>35)$ & 212 & 13 & 0.67 & $0.58-0.76$ & 491 & 30 & 0.82 & $0.76-0.88$ \\
\hline \multicolumn{9}{|l|}{ Smoking } \\
\hline Never $§$ & 3224 & 18 & 1.0 & & 6294 & 36 & 1.0 & \\
\hline Former & 2090 & 19 & 0.94 & $0.90-0.99$ & 4359 & 39 & 1.02 & $0.99-1.04$ \\
\hline Current & 201 & 9 & 0.49 & $0.42-0.56$ & 499 & 23 & 0.76 & $0.71-0.80$ \\
\hline \multicolumn{9}{|l|}{ Alcoholic drinks/day** } \\
\hline Meet guidelines ${ }^{\S}$ & 2717 & 19 & 1.0 & & 5278 & 37 & 1.0 & \\
\hline $\begin{array}{l}\text { Exceed guidelines } \\
\text { Weekly exercise }\end{array}$ & 1856 & 19 & 0.98 & $0.93-1.03$ & 3731 & 37 & 1.03 & $0.99-1.06$ \\
\hline $\begin{array}{l}\text { Weekly exercise } \\
\text { Sufficient }\end{array}$ & 3917 & 20 & 1.0 & & 7585 & 38 & 1.0 & \\
\hline Insufficient & 1355 & 16 & 0.83 & $0.78-0.87$ & 2920 & 34 & 0.91 & $0.88-0.94$ \\
\hline Sedentary & 182 & 10 & 0.53 & $0.46-0.62$ & 483 & 26 & 0.71 & $0.66-0.77$ \\
\hline \multicolumn{9}{|l|}{ Overall health } \\
\hline Poor & 81 & 13 & 0.63 & $0.51-0.78$ & 215 & 34 & 0.88 & $0.79-0.98$ \\
\hline Fair & 517 & 14 & 0.70 & $0.64-0.76$ & 1293 & 35 & 0.92 & $0.88-0.97$ \\
\hline Good & 1769 & 17 & 0.85 & $0.80-0.90$ & 3822 & 37 & 0.98 & $0.95-1.01$ \\
\hline Very good ${ }^{\delta}$ & 2204 & 20 & 1.0 & & 4111 & 38 & 1.0 & \\
\hline Excellent & 885 & 20 & 1.01 & $0.94-1.08$ & 1558 & 35 & 0.96 & $0.92-1.01$ \\
\hline \multicolumn{9}{|l|}{ Quality of life } \\
\hline Poor & 62 & 12 & 0.63 & $0.49-0.79$ & 158 & 30 & 0.80 & $0.71-0.91$ \\
\hline Fair & 389 & 14 & 0.72 & $0.65-0.80$ & 958 & 35 & 0.91 & $0.86-0.96$ \\
\hline Good & 1362 & 16 & 0.82 & $0.77-0.87$ & 3015 & 36 & 0.93 & $0.90-0.97$ \\
\hline Very good $\S$ & 2139 & 20 & 1.0 & & 4156 & 38 & 1.0 & \\
\hline Excellent & 1473 & 21 & 1.09 & $1.02-1.15$ & 2614 & 37 & 1.01 & $0.97-1.04$ \\
\hline \multicolumn{9}{|l|}{ Need help with daily tasks } \\
\hline $\mathrm{No}^{\S}$ & 5292 & 18 & 1.0 & & 10588 & 36 & 1.0 & \\
\hline Yes & 225 & 13 & 0.76 & $0.67-0.86$ & 567 & 32 & 0.91 & $0.85-0.97$ \\
\hline
\end{tabular}

Abbreviations: FOBT faecal occult blood test; RR relative risk; $\mathrm{Cl}$ confidence interval

*Includes FOBT, colonoscopy or sigmoidoscopy

${ }^{\dagger}$ Adjusted for age, gender and family history of cancer. Numbers may not add up to total due to missing values

${ }^{\ddagger}$ Body mass index (BMI) ranges as classified by the World Health Organization?

§Reference category

${ }^{* *}$ One standared drink per day for women and two for men. NHMRC Dietary Guidelines for Australian Adults ${ }^{8}$

${ }^{\dagger \dagger}$ At least 150 minutes of activity and at least five sessions of activity per week. Active Australia Survey ${ }^{7}$

supplements and aspirin for the heart was associated with uptake of any colorectal cancer test (Table 3).

\section{DISCUSSION}

Our data show that there are significant demographic and lifestyle differences between people who do and do not undertake colorectal cancer testing in NSW, Australia. Colorectal cancer testing was found to be reduced among women, those of low socioeconomic status, participants without a partner and those with English as a second language. Uptake was high among participants with a family history of cancer, those who reported uptake of other cancer screening tests, and retirees. Participants who lived in regional areas were more likely to have taken a FOBT than those living in a major city or those in remote areas, in fact, participants in remote areas were significantly less likely to have had any test for colorectal cancer in the last five years. Uptake was particularly low among current smokers, sedentary participants and those who do not include fruit and/or vegetables in their diet. Overall, these data indicate that baseline screening uptake was very low at the commencement of the National Bowel Cancer Screening Programme.

Participants who speak a language other than English had almost two-fold lower rates of colorectal cancer testing than English-only speakers, and a similar finding was reported in the Australian Bowel Cancer Screening Pilot. ${ }^{11}$ These findings suggest that colorectal cancer testing maybe low in some migrant groups, as has been found in the USA. ${ }^{12,13}$ Indeed, it is possible that some migrant groups significantly under-utilize health services in general. This is an avenue for further exploration, especially considering that $23 \%$ of the population of NSW was born outside of Australia. ${ }^{14}$

Lifestyle factors that have been associated with an increased risk of colorectal cancer in many studies, in particular being obese, physically inactive or a current smoker, ${ }^{15}$ were significantly related to low colorectal testing behaviour in this cohort. Likewise, intake of fruit, vegetables and grains, which are potentially protective against colorectal cancer, ${ }^{15}$ were low in those who were not tested for colorectal cancer in the past five years. These subgroups are possibly resistant to health messages and may require targeted interventions related to cancer prevention and screening.

There was an overall tendency of colorectal test uptake to be associated with health-conscious behaviours in general, and behaviours that involve contact with the medical system. For example, participants who took other cancer screening tests, met recommendations for weekly physical activity, met dietary recommendations, used reduced-fat milk and took multivitamins, were more likely to be tested than those who did not. Participants who felt that their overall health and quality of life were very good or excellent were more likely to report colorectal testing (and FOBT in 
Table 3 Distribution of colorectal test uptake by dietary factors

\begin{tabular}{|c|c|c|c|c|c|c|c|c|}
\hline \multirow[b]{2}{*}{ Dietary factors ${ }^{\dagger}$} & \multicolumn{4}{|c|}{ FOBT only $n=5518$} & \multicolumn{4}{|c|}{ All tests* $n=11158$} \\
\hline & Uptake (n) & Uptake (\%) & $\mathrm{RR}^{\ddagger}$ & $95 \% \mathrm{Cl}$ & Uptake (n) & Uptake (\%) & $\mathrm{RR}^{\ddagger}$ & $95 \% \mathrm{Cl}$ \\
\hline \multicolumn{9}{|l|}{ Red meat/week } \\
\hline $1-4$ serves $^{\S}$ & 4209 & 18 & 1.0 & & 8546 & 37 & 1.0 & \\
\hline$>4$ serves & 1072 & 19 & 1.01 & $0.96-1.08$ & 2068 & 37 & 0.97 & $0.93-1.00$ \\
\hline 0 serves & 206 & 14 & 0.80 & $0.71-0.91$ & 453 & 31 & 0.87 & $0.80-0.94$ \\
\hline \multicolumn{9}{|l|}{ Processed meat/week } \\
\hline 0 serves $^{\S}$ & 1524 & 18 & 1.0 & & 3040 & 37 & 1.0 & \\
\hline 1 or more serves & 3362 & 18 & 0.96 & $0.91-1.01$ & 6736 & 37 & 0.97 & $0.94-1.00$ \\
\hline \multicolumn{9}{|l|}{ Fruit/day } \\
\hline 2 or more serves $\S$ & 3443 & 19 & 1.0 & & 6777 & 38 & 1.0 & \\
\hline$<2$ serves & 419 & 17 & 0.87 & $0.80-0.96$ & 845 & 35 & 0.92 & $0.87-0.97$ \\
\hline 0 serves & 190 & 13 & 0.66 & $0.58-0.76$ & 414 & 29 & 0.77 & $0.71-0.84$ \\
\hline \multicolumn{9}{|l|}{ Vegetables/day } \\
\hline 5 or more serves ${ }^{\S}$ & 1574 & 20 & 1.0 & & 3064 & 39 & 1.0 & \\
\hline$<5$ serves & 3002 & 18 & 0.91 & $0.86-0.96$ & 6018 & 37 & 0.96 & $0.93-0.99$ \\
\hline 0 serves & 61 & 12 & 0.57 & $0.45-0.72$ & 157 & 30 & 0.79 & $0.69-0.90$ \\
\hline \multicolumn{9}{|l|}{ Unprocessed cereals** } \\
\hline Sufficient ${ }^{\dagger}$ & 4328 & 20 & 1.0 & & 8413 & 39 & 1.0 & \\
\hline Insufficient & 486 & 15 & 0.76 & $0.69-0.82$ & 1045 & 33 & 0.86 & $0.82-0.90$ \\
\hline None & 193 & 13 & 0.63 & $0.55-0.72$ & 460 & 31 & 0.80 & $0.74-0.86$ \\
\hline \multicolumn{9}{|l|}{ Milk } \\
\hline Whole $\S$ & 1363 & 15 & 1.0 & & 2913 & 31 & 1.0 & \\
\hline Reduced fat & 2166 & 21 & 1.42 & $1.34-1.51$ & 4195 & 40 & 1.29 & $1.24-1.34$ \\
\hline Skim & 1212 & 19 & 1.38 & $1.29-1.48$ & 2472 & 39 & 1.28 & $1.23-1.34$ \\
\hline Soy & 397 & 21 & 1.47 & $1.33-1.62$ & 789 & 41 & 1.34 & $1.27-1.42$ \\
\hline Other & 77 & 15 & 1.05 & $0.85-1.30$ & 176 & 34 & 1.14 & $1.01-1.28$ \\
\hline Don'ł drink milk & 279 & 18 & 1.24 & $1.10-1.39$ & 546 & 35 & 1.13 & $1.06-1.22$ \\
\hline \multicolumn{9}{|l|}{ Vitamin supplements } \\
\hline $\mathrm{No}^{\S}$ & 4151 & 17 & 1.0 & & 8514 & 36 & 1.0 & \\
\hline Yes & 1367 & 20 & 1.18 & $1.11-1.24$ & 2644 & 38 & 1.09 & $1.06-1.13$ \\
\hline \multicolumn{9}{|l|}{ Aspirin } \\
\hline $\mathrm{No}^{\S}$ & 4157 & 17 & 1.0 & & 8386 & 35 & 1.0 & \\
\hline Yes & 254 & 18 & 1.06 & $0.94-1.18$ & 528 & 38 & 1.06 & $1.00-1.13$ \\
\hline Yes for the heart & 1107 & 20 & 1.09 & $1.03-1.16$ & 2244 & 40 & 1.07 & $1.03-1.10$ \\
\hline
\end{tabular}

Abbreviations: FOBT faecal occult blood test; RR relative risk; $\mathrm{Cl}$ confidence interval

*Includes FOBT, colonoscopy or sigmoidoscopy

${ }^{\dagger}$ Recommended by the NHMRC Dietary Guidelines for Australian Adults ${ }^{8}$

${ }^{\ddagger}$ Adjusted for age, gender and family history of cancer. Numbers may not add up to total due to missing values

${ }^{\S}$ Reference category

**At least four serves a week for women and six for men

particular) than those with poorer ratings. The healthconscious and healthy respondents in this cohort are therefore possibly more educated about the purposes of screening than the rest of the cohort.

Previous studies have found that barriers to screening include a lack of symptoms or perceived good health, indicating a lack of knowledge regarding the purposes of screening, $^{11,12,16,17}$ embarrassment/distaste for stool collection, and lack of time/don't care. ${ }^{16,17}$ Evidence suggests that colorectal screening participation in Australia is likely to be increased by encouragement from general practitioners and information materials provided with screening invitations. ${ }^{11,16-20}$ There are no Australian studies, to our knowledge, that aim to increase participation in particular subgroups of the population such as migrant groups, those who are resistant to health messages, or those with low socioeconomic indicators. However, the National Bowel Screening Programme has just begun and so there is scope to examine these issues in the future. Using the follow-up questionnaires of the 45 and Up (every five years) we will be able to trace changes in colorectal screening participation as the national programme is established.

A limitation of our study is that, like most studies of colorectal screening, screening history was derived from selfreport. A meta-analysis of validation studies on self-reported cancer screening uptake in the USA found that self-reported versus documented history of FOBT and colorectal endoscopy had reasonably high sensitivity $(0.82$ and 0.79 , respectively) and specificity $(0.78$ and 0.90$) .{ }^{21}$ These findings suggest that in the USA, FOBT was over-reported by participants more often than under-reported, and colorectal endoscopy was under-reported by participants more often than over-reported. These discrepancies would have partly been due to participants misremembering the date of the screening event and possibly due to incomplete documentation in medical records. The accuracy of self-reported colorectal screening uptake in Australia has not, to our knowledge, been assessed but if the same trends occurred here, we would expect that the prevalence of self-reported FOBT use in the 45 and Up Study was biased upwards and that use of endoscopy was biased downwards. However, a more specific problem with self-report in this study is that although the questionnaire specifically asked about 'screening' there was no information regarding the difference between screening and diagnostic testing and so we were not able to exclude those participants who received endoscopy because of symptoms. However, the associations we reported involving FOBT specifically are likely to represent some form of screening rather than diagnostic testing. Furthermore, outcomes of analyses including all tests did not differ greatly to those with FOBT.

The $18 \%$ study response rate indicates that our cohort may not be fully representative of the entire population, however, like most long-term cohort studies, the 45 and 
Up Study is designed to provide sufficient heterogeneity for valid comparisons within the cohort, rather than specific estimates of prevalence of exposure in the population. Indeed, the age-specific rates of colorectal cancer testing in the 45 and Up Study $(31 \%, 42 \%$ and $37 \%$ for the $50-59$, 60-69 and 70+ year age groups, respectively) are higher than those seen in the 2004 NSW Population Health Survey $(25 \%, 30 \%$ and $29 \%$, for the 50-59, 60-69 and $70+$ year age groups, respectively, based on 8196 respondents and a study participation rate of $67.6 \%),{ }^{5}$ indicating that, like many other cohort studies, the 45 and Up cohort is likely to be more health conscious than the general population. Potential bias resulting from the 'healthy cohort' effect, if it is present, generally leads to more conservative results, due to reduced representation of population groups who have more extreme health behaviours, such as those who are mentally or physically ill or marginalized for some other reason. Hence, the relative risk for factors associated with colorectal cancer screening may be somewhat closer to the null than might be seen among comparisons of community members who do not tend to participate in studies of this type. Caution must also be exercised when interpreting any negative results. These considerations, and the variability in colorectal cancer screening across all demographic and lifestyle variables within the cohort, ${ }^{6}$ along with the fact that most of the demographic factors associated with low colorectal screening attendance in our study are consistent with the limited evidence available from Australia ${ }^{11,16,22,23}$ and elsewhere, ${ }^{24-27}$ suggests that the overall findings regarding comparisons of those who do and do not undertake testing for colorectal cancer are likely to be generalizable.

The findings outlined here suggest that there are subgroups of the Australian population that may be less likely to undergo colorectal cancer screening. Future populationbased colorectal cancer screening programmes may benefit from strategies to improve uptake in these groups.

\section{Authors' affiliations}

Marianne F Weber, Research Fellow, Cancer Epidemiology Research Unit, The Cancer Council NSW, PO Box 572, Kings Cross 1340, Australia

Emily Banks, NHMRC Fellow and Scientific Director, The 45 and Up Study, National Centre for Epidemiology and Population Health, The Australian National University, Acton ACT 0200, Australia

Robyn Ward, Professor, Prince of Wales Clinical School, University of NSW, Director of Area Cancer Services SESIAHS, Prince of Wales Hospital, Randwick NSW 2031, Australia

Freddy Sitas, Director, Cancer Research Division, The Cancer Council NSW, PO Box 572, Kings Cross 1340, Australia

\section{ACKNOWLEDGEMENTS}

The 45 and Up Study is auspiced by the Sax Institute in collaboration with Study Partners: The Cancer Council of New South Wales; the New South Wales Division of the National Heart Foundation of Australia; the New South Wales Department of Health; beyondblue; and the New South Wales Department of Ageing, Disability and Home Care.

\section{REFERENCES}

1 Ferlay J, Bray F, Pisani P, et al. GLOBOCAN 2002 Cancer Incidence, Mortality and Prevalence Worldwide. IARC CancerBase No. 5, version 2.0. Lyon: IARCPress, 2004

2 Mandel JS, Church TR, Bond JH, et al. The effect of fecal occult-blood screening on the incidence of colorectal cancer. N Engl J Med 2000:343: 1603-7

3 Winawer SJ, Zauber AG, O'Brien M, et al. Randomized comparison of surveillance intervals after colonoscopic removal of newly diagnosed adenomatous polyps. The National Polyp Study Workgroup. N Engl J Med 1993:328:901-6

4 Australian Cancer Network Colorectal Cancer Guidelines Revision Committee. Clinical Practice Guidelines for the Prevention, Early Detection and Management of Colorectal Cancer. Sydney: The Cancer Council Australia and Australian Cancer Network, 2005

5 Population Health Division. The Health of the People of New South Wales - Report of the Chief Health Officer. Sydney: NSW Department of Health, 2006

645 and Up Study Collaborators. Cohort Profile: The 45 and Up Study. Int $J$ Epidemiol 2007 Epub ahead of print. DOI: 10.1093/ije/dym 184

7 The Australian Institute of Health and Welfare. The Active Australia Survey a guide and manual for implementation, analysis and reporting. Canberra: AlHW, 2003

8 National Health \& Medical Research Council. Dietary Guidelines for Australian Adults. Canberra: Commonwealth of Australia, 2003

9 The World Health Organization. Obesity: preventing and managing the global epidemic. WHO Technical Report Series No. 894. Geneva: WHO, 2000

10 Spiegelman D, Hertzmark E. Easy SAS calculations for risk or prevalence ratios and differences. Am J Epidemiol 2005;162:199-200

11 Australian Government Department of Health and Ageing. The Australian Bowel Cancer Screening Pilot Program and Beyond: Final Evaluation Report. Canberra: Commonwealth of Australia, 2005

12 Kandula NR, Wen M, Jacobs EA, et al. Low rates of colorectal, cervical, and breast cancer screening in Asian Americans compared with non-Hispanic whites: cultural influences or access to care? Cancer 2006; 107: 184-92

13 Wong ST, Gildengorin G, Nguyen T, et al. Disparities in colorectal cancer screening rates among Asian Americans and non-Latino whites. Cancer 2005: 104:2940-7

14 Australian Bureau of Statistics. Census of Population and Housing. Australia: Commonwealth of Australia, 2006

15 Potter JD. Colorectal cancer: molecules and populations. J Natl Cancer Inst 1999:91:916-32

16 Forbes GM, Fritschi L, Mendelson RM, et al. Influences on participation in a community-based colorectal neoplasia screening program by virtual colonoscopy in Australia. Aust NZ J Public Health 2004;28:283-7

17 Tong S, Hughes K, Oldenburg BB, et al. Colorectal cancer screening with faecal occult blood testing: community intention, knowledge, beliefs and behaviour. Asia Pac J Public Health 2006; 18:16-23

18 Cole SR, Young GP, Byrne D, et al. Participation in screening for colorectal cancer based on a faecal occult blood test is improved by endorsement by the primary care practitioner. J Med Screen 2002:9:147-52

19 Cole SR, Smith A, Wilson C, et al. An advance notification letter increases participation in colorectal cancer screening. J Med Screen 2007; 14:73-5

20 Salkeld GP, Solomon M, Short L, et al. Measuring the importance of attributes that influence consumer attitudes to colorectal cancer screening Aust NZ J Surg 2003;73:128-32

21 Rauscher GH, Johnson TP, Cho Yl, et al. Accuracy of self-reported cancer screening histories: a meta-analysis. Cancer Epidemiol Biomarkers Prev 2008; 17:748-57

22 Carriere P, Baade P, Newman B, et al. Cancer screening in Queensland men. Med J Aust 2007; 186:404-7

23 Cockburn J, Paul C, Tzelepis F, et al. Screening for bowel cancer among NSW adults with varying levels of risk: a community survey. Aust NZ J Public Health 2002; 26:236-41

24 Chao A, Connell CJ, Cokkinides V, et al. Underuse of screening sigmoidoscopy and colonoscopy in a large cohort of US adults. Am J Public Health 2004:94:1775-81

25 loannou GN, Chapko MK, Dominitz JA. Predictors of colorectal cancer screening participation in the United States. Am J Gastroenterol 2003:98:2082-91

26 Liang SY, Phillips KA, Nagamine $M$, et al. Rates and predictors of colorectal cancer screening. Prev Chronic Dis 2006;3:A1 17

27 Sutton S, Wardle J, Taylor T, et al. Predictors of attendance in the United Kingdom flexible sigmoidoscopy screening trial. J Med Screen 2000; 7:99-104 